\title{
Anti-f in a 24- Year Old Male: A Case Study
}

\author{
ELEANOR K JATOR, ETHAN PEDDE
}

\begin{abstract}
This is a case study of a 24-year old male, having total knee arthroplasty, who is found to have an anti-f antibody, and denies history of previous blood product injection or blood transfusion. The anti- $\mathrm{f}$ antibody is produced due to exposure to the $\mathrm{f}$ antigen, and is one of the Rh blood group system's compound antigens expressed when the $\mathrm{c}$ and $\mathrm{e}$ alleles are in the cis position on the Rh chromosome. Patients with anti-f requiring transfusion could safely be transfused with units of blood lacking both the $\mathrm{c}$ and $\mathrm{e}$ antigens and units lacking only the $\mathrm{c}$ antigen.
\end{abstract}

INDEX TERMS: Anti-f, f antigen, blood transfusion.

Clin Lab Sci 2010;23(2):68

Eleanor K. Jator, PhD MLS(ASCP), Austin Peay State University, Clarksville, TN 37044

Ethan Pedde, MLS (ASCP), Indian Path Medical Center, Kingsport, TN 37660

Address for Correspondence: Associate Professor, Medical Technology Program, Austin Peay State University, 601 College Street, Clarksville, TN 37044; jatore@apsu.edu, Phone: 931-221-6498; Fax: 931-221-6452

ACKNOWLEDGEMENTS: The authors would like to acknowledge Gail Roberson and the Memorial Healthcare System Blood Bank Chattanooga, TN.

\section{CASE PRESENTATION}

A 24-year-old Hispanic male was admitted for a total left knee arthroplasty. During his pre-surgical evaluation, eleven days prior to the operation, the patient's hemoglobin and hematocrit were found to be $14.2 \mathrm{~g} / \mathrm{dL}$ and $41.4 \%$, respectively (Table 1 ). No preoperative autologous units were donated; however, 350 $\mathrm{ml}$ of salvaged blood was reinfused during the procedure.
Table 1: Pre-surgical laboratory results of patient

\begin{tabular}{lcc}
\hline Tests & Results & Reference Range \\
Hemoglobin & $14.2 \mathrm{~g} / \mathrm{dL}$ & $14-18 \mathrm{~g} / \mathrm{dL}$ \\
Hematocrit & $41.4 \%$ & $42-52 \%$ \\
ABO group type & $\mathrm{O}$ & \\
Rh & Positive & \\
Antibody screen & Positive & \\
Antibody Panel & Positive, & \\
Autocontrol & Negative &
\end{tabular}

The patient's 24 hour post-surgical results revealed that his hemoglobin and hematocrit were $10.1 \mathrm{~g} / \mathrm{dL}$ and $28.9 \%$ respectively (Table 2 ). Thereafter, there was a steady decrease despite the salvaged blood reinfusion. An explanation for this decrease was attributed to postoperative blood drainage, considering the scope of the operation performed and the pre-surgical negative autocontrol result (Table 1). Day two post-surgery, the patient's hemoglobin and hematocrit dropped to 8.2 $\mathrm{g} / \mathrm{dL}$ and $23.9 \%$, which warranted transfusion per hospital protocol (Table 2).

Table 2: Post surgical results

\begin{tabular}{lccc}
\hline Day & Hemoglobin & Hematocrit & Units transfused \\
One: & $10.1 \mathrm{~g} / \mathrm{dL}$ & $28.9 \%$ & \\
Two: & $8.2 \mathrm{~g} / \mathrm{dL}$ & $23.9 \%$ & $2 \mathrm{c}$ - negative \\
& & & $\begin{array}{c}\text { PRBC units transfused } \\
\text { Three: }\end{array}$ \\
& $8.6 \mathrm{~g} / \mathrm{dL}$ & $23.8 \%$ & $\begin{array}{c}\mathrm{c} \text { - negative } \\
\text { PRBC units transfused }\end{array}$ \\
Four: & $9.6 \mathrm{~g} / \mathrm{dL}$ & $27.3 \%$ & \\
Six: & $10.8 \mathrm{~g} / \mathrm{dL}$ & $31.2 \%$ & \\
\hline
\end{tabular}

The physician ordered a type and screen and four units of packed red cells. The patient's specimen was obtained and initial results indicated that the antibody screen was positive with a negative autocontrol using the gel method (Table 1). The identification panel revealed an anti-f antibody (Table 4). The American Red Cross reference laboratory was contacted to provide more information on the nature of this antibody. Then the antibody identification process was completed by antigen typing the patient's red blood cells for $\mathrm{c}$ and $\mathrm{e}$ 


\section{CLINICAL PRACTICE}

antigens. The cells were c-positive and e-negative as shown on Table 3.

Table 3: Antibody screen and antigen typing results of patient

$\begin{array}{cc}\text { Antibody Screen } & \\ \text { Screen cells } & \text { Results } \\ \text { I } & 0 \\ \text { II } & 0 \\ \text { III } & 2+ \\ \text { Autocontrol } & \text { Negative } \\ \text { Antigen typing results } & \\ \text { Antisera } & \text { Results } \\ \text { e } & 0 \\ \text { c } & \text { Positive }\end{array}$

Once this antibody was confirmed, the patient's history was further investigated to determine whether the patient had been transfused, had surgery or another condition requiring the use of blood or blood products. While the patient denied receiving blood, the history revealed an earlier gunshot wound which made it likely that the patient had received a transfusion, and simply misunderstood the question or was unable to recall.

Two c-negative units were transfused on day two postsurgery with no adverse reaction. However, on day three, the patient's hemoglobin and hematocrit results remained constant with an $8.6 \mathrm{~g} / \mathrm{dL}$ hemoglobin compared to $8.2 \mathrm{~g} / \mathrm{dL}$ and a $23.8 \%$ hematocrit compared to $23.9 \%$ on post-surgical day two (Table 2 ).

The expected rise of 1 to $1.5 \mathrm{~g} / \mathrm{dL}$ of hemoblogin and 3 to $5 \%$ hemocrit for each transfused unit of blood did not occur. Continued blood loss was the probable explanation for this event as considerable blood loss is associated with total knee arthroplasty. ${ }^{1}$ No additional serology was performed on the patient because the first and second set of transfusions occurred within 24 hours. Two more c-negative units were transfused on post-surgical day three, and the patient's hemoglobin and hematocrit levels increased steadily over the next few days, with a final hemoglobin value of $10.8 \mathrm{~g} / \mathrm{dL}$ and hematocrit of $31.2 \%$ at discharge.

What is known about the $\mathrm{f}$ (ce) antigen?

The $\mathrm{f}$ antigen is in the Rh blood group system with the International Society of Blood Transfusion (ISBT) number 004006 . It is in the Rh blood group system present in 65\% Caucasians, 92\% blacks and $12 \%$ Asians. ${ }^{3}$ The $\mathrm{Rh}$ blood group system is made up of many antigens; some of which are compound antigens.

The $\mathrm{f}$ antigen is one of the Rh blood group system's compound antigens. These compound antigens are the result of positional effects of the alleles on the chromosomes. ${ }^{3}$ Cis products of these genes are expressed

Table 4: Antibody identification panel

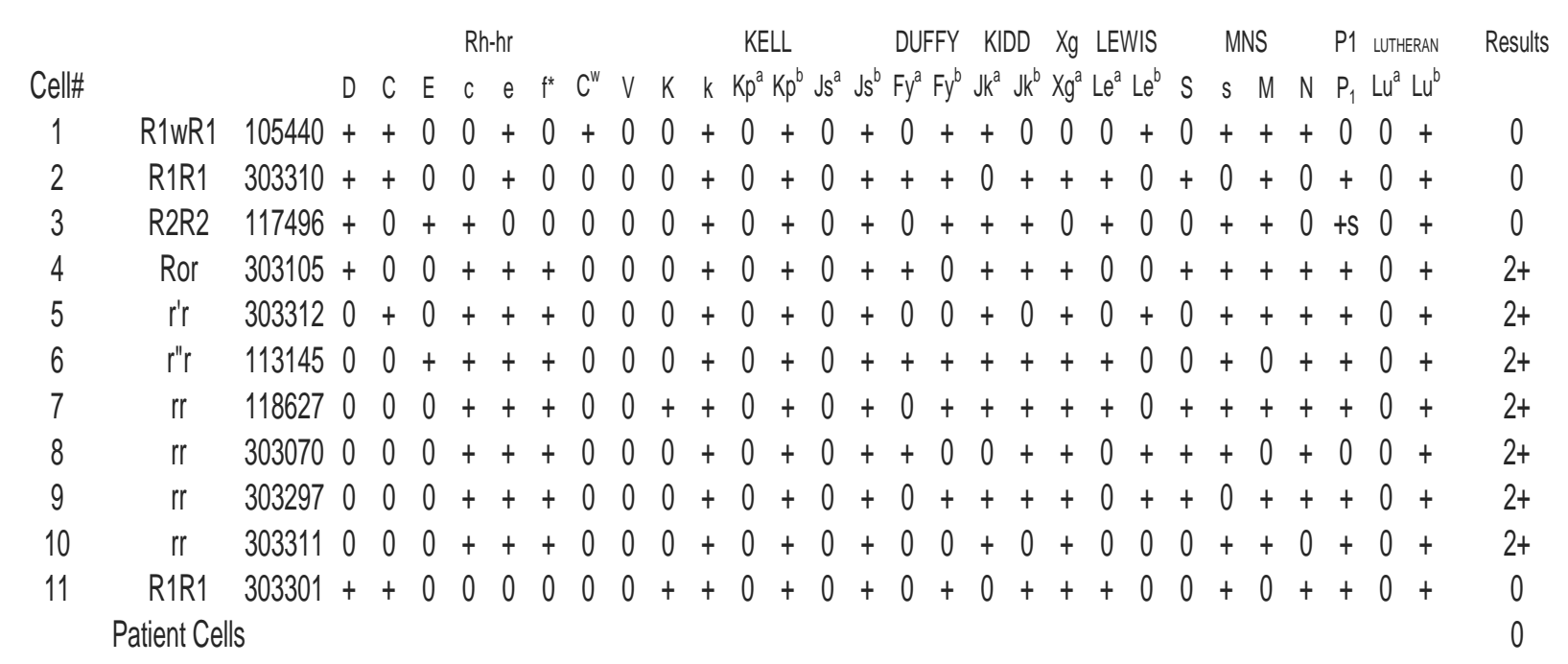




\section{CLINICAL PRACTICE}

when the alleles are on the same haplotype. ${ }^{3}$ The $f$ antigen is believed to be expressed when the $\mathrm{c}$ and $\mathrm{e}$ alleles are in the cis position. ${ }^{3,4}$ This antigen can be found in individuals with $c d e, c D e, c D^{u} e$ genes resulting in expression of the e antigen, $c$ antigen and $f$ antigen (ce). ${ }^{4}$ This is different in individuals having the $C D e / c D E$ genes in which the $\mathrm{c}$ and $\mathrm{e}$ genes are on different chromosomes. An individual having $C D e / c D E$ genes will not express the compound $\mathrm{f}(\mathrm{ce})$ antigen, but will express the $\mathrm{e}$ and the $\mathrm{c}$ antigens $(\mathrm{e}+, \mathrm{c}+)$.

The $\mathrm{f}$ antigen was identified in 1953 by absorption tests on red cells with different genotypes. ${ }^{5}$ It was reported that cells with the following genotypes did not react with anti-f--CDe/CDe, $\quad c D E / c D E, \quad C D e / c D E$ and $C d e / c d E$--while red cells with the following genotypes reacted with anti-f--cde/cde, $c D e / c d e, C D e / c d e, c D E / c d e$, $c d E / c d e, C D E / c D e$ and $C d E / c d e .^{5}$ This study confirmed the antigenic identity of the $f$ antigen as well as its molecular basis.

An interesting finding about the $\mathrm{f}$ antigen is that it is also expressed when only the $\mathrm{D}$ and $\mathrm{c}$ antigens are present (cD-). 3,6 This phenomenon can be confusing, but it has been explained that the $\mathrm{D}$ is dominant in this scenario with either the reduced expression of $\mathrm{c}$ or a qualitatively different expression of $c$. In this case the $f$ antigen expression is greatly reduced ${ }^{3,7}$ and only approximately half the number of antigenic sites is expressed. ${ }^{7}$ One would expect the $f$ antigen not to be expressed in the absence of the e antigen. The $f$ antigen is known to be resistant to enzymes and other chemicals including Ficin, papain, trypsin, pronase, sialidase, DTT. $^{3}$

\section{Differences in Anti-f}

Anti-f was first discovered in 1953 in a multiply transfused 30-year-old Caucasian male who suffered from hemophilia., ${ }^{3,7}$ His genotype was $C D e / c D E$, which implies that it was not possible for him to express the $f$ antigen since the $\mathrm{c}$ and $\mathrm{e}$ antigens were in the trans position. ${ }^{4}$ Anti-f has been found to be qualitatively different. Anti-f is expected to react with cells containing the ce antigen but has been reported to react with cells typing $\mathrm{cD}-.{ }^{4}$ Cells with the $\mathrm{cD}$ - phenotype have been reported to react with anti- $\mathrm{f}^{7}$, but failed to react with anti-e sera containing anti-f. This antibody might have some slight differences. Qualitative differences have also been reported with anti-f produced by $C d e / c D E$ individuals compared to anti-f produced by $c D e / c D E$ individuals.

Just as with other antibodies, it is possible not to make anti-f if exposed to red cells expressing the $f$ antigen. ${ }^{5}$ The anti-f antibody is usually IgG although there are some IgM examples. It does not bind complement and has been reported to be present in some anti-c and antie reagent antisera. The antibody does have clinical significance as it can cause mild hemolytic transfusion reactions and hemolytic disease of the newborn. ${ }^{3}$ Autoanti $\mathrm{f}$ has also been isolated. ${ }^{3}$

Should we rely on patients to provide an accurate medical history?

Patients are often an unreliable source of information about past treatment. This can be the result of treatment given while the patient was in varying degrees of consciousness, or that caregivers did not properly explain the treatment being provided. Often, however, the problem is simply a matter of communication. For example, while a patient may give a negative reply when asked if he has had a transfusion, changing the term to "received blood" can result in a detailed explanation of how many units of each type of blood product was received. The key to receiving an accurate history is often a matter of simply asking the questions in a way the patient understands.

\section{CONCLUSION}

The patient's red cells in this case study typed cD-. Since the e antigen is absent, one would expect the reaction strength of the patient's cells with examples of anti-f to be on the weak side. In the case of this 24-year old, reaction strength of his serum with screen cells were all $2+$ (Table 3). Similar reaction strengths were observed with panel cells (Table 4) which confirms the weakened expression of the antigen. Possibly there is some $f$ antigen present in the patient's red cells that may cause production of a qualitatively different type of anti-f compared to the one produced with missing $\mathrm{c}$ and e antigens.

After antigen typing the patient's cells, four O positive, c-negative units were cross-matched by the gel method 


\section{CLINICAL PRACTICE}

and were found to be compatible. Individuals with anti$\mathrm{f}$ who express only the $\mathrm{c}$ antigen can be safely transfused with units missing the $\mathrm{c}$ antigen.

\section{REFERENCES}

1. Moonen AFCM, Neal TD, Pilot P. Perioperative blood management in orthopaedic elective surgery. A critical review of literature. Injury. 2006:37:S11-S16.

2. Bern MM, Bierbaum BE, Katz JN, Losina E. Autologous blood donation and subsequent blood use in patients undergoing total knee arthroplasty. Trans Med. 2006;16(5):313-9.

3. Reid ME, Lomas-Francis C. The blood group antigen factsbook. 2nd ed. Amsterdam:Boston Elsevier/Academic press;2004.

4. Rosenfield RE, Vogel P, Gibbel N, Sanger R, Race RR. A new Rh antibody, Anti-f. Brit. Med. J. [Internet] 1953 May 2[Cited
2009 March 27];1:975. Available from http://www.bmj.com/ $\mathrm{cgi} /$ reprint $/ 1 / 4817 / 975$ ? maxtoshow $=\&$ HITS $=10 \&$ hits $=10 \& \mathrm{R}$

ESULTFORMAT $=\&$ fulltext $=$ rosenfield $\% 2 \mathrm{C}+$ sanger\&searchid $=1 \&$ FIRSTINDEX=0\&resourcetype=HWCIT

5. Sanger R, Race RR, Rosenfield RE, Vogel P, Gibbel N. Anti f and the new Rh antigen it defines. Proc. Nat. Acad. Sci. [Internet] 1953 August 1[Cited 2009 March 31];39(8):82434. Available from http://www.pnas.org/content/39/8/8 24.full.pdf + html?sid=500561b6-22a8-4202-9cad-bb519c2c719 3

6. Issitt PD. Review: The Rh blood group system: an historical calendar. Immunohematolo 2005;21(4):155-63.

7. Race RR, Sanger R. Blood groups in man.4th ed. Blackwell Scientific Publications:Oxford; 1962.

The peer-reviewed Clinical Practice Section seeks to publish case studies, reports, and articles that are immediately useful, are of a practical nature, or contain information that could lead to improvement in the quality of the clinical laboratory's contribution to patient care, including brief reviews of books, computer programs, audiovisual materials, or other materials of interest to readers. Direct all inquiries to Libby Spence, PhD, CLS(NCA), Clin Lab Sci Clinical Practice Editor, University of Mississippi Medical Center, 2500 North State Street, Jackson, MS 39216, lspence@umc.edu. 